\title{
论文
}

\section{珠江口沉积物溶解性有机质来源及光谱特征的 空间变化}

徐阳 ${ }^{1}$, 李朋辉 ${ }^{2}$, 张传伦 ${ }^{2,3}$, 王鹏 ${ }^{1^{*}}$

1. 同济大学海洋地质国家重点实验室, 上海 200092;

2. 南方科技大学深圳市海洋地球古菌组学重点实验室, 深圳 518055 ;

3. 青岛海洋科学与技术国家实验室海洋地质过程与环境功能实验室, 青岛 266237

* 通讯作者, E-mail: pengwang@tongji.edu.cn

收稿日期: 2020-03-07; 收修改稿日期: 2020-07-31; 接受日期: 2020-08-14; 网络版发表日期: 2020-10-28 国家自然科学基金项目(批准号：41776134)、青岛海洋科学与技术国家实验室海洋地质过程与环境功能实验室项目(编号：MGQNLMTD201810)和深圳海洋地球古菌组学重点实验室项目(编号: ZDSYS201802081843490)资助

摘要作为海陆交互作用的重要区域, 河口在海洋碳循环中扮演着重要角色. 近年来, 溶解性有机质(dissolved organic matter, DOM) 在河口区的来源、降解和保存一直是关注的热点. 本研究结合三维荧光光谱和紫外可见吸 收光谱, 对珠江口3 个沉积柱(S1、S2、S3 站位, 盐度依次增加)孔隙水溶解性有机质的空间分布和来源进行了表 征分析. 利用平行因子分析(parallel factor analysis, PARAFAC) 方法对三维荧光光谱数据进行解析共得到5种荧光 组分: 类腐殖质组分 $\mathrm{C} 1 、 \mathrm{C} 3 、 \mathrm{C} 4$, 以及类蛋白荧光组分 $\mathrm{C} 2$ 和 $\mathrm{C} 5$. 三个站位的 $\mathrm{C} 2$ 组分同沉积物微生物DNA浓度表 现出显著的正相关关系 $\left(R^{2}=0.69, P<0.01\right)$, 说明类蛋白组分 $\mathrm{C} 2$ 可能主要来源于原位微生物的分解代谢. C5 同DNA 浓度相关性较弱 $\left(R^{2}=0.40, P<0.05\right)$, 推测是混入了荧光峰同类蛋白组分十分接近的酚类化合物所致. 类腐殖质荧 光组分来源复杂, S1站位类腐殖质荧光组分含量最高(1.45 8.83R.U.), 推测是受到了显著的陆源输入影响. S2 和 S3 站位3种类腐殖质荧光组分含量很低( $<1$ R.U. .), 且分布规律十分相似, 可能主要来源于水体和沉积物藻类微生物 的代谢释放.三个站位的腐质化指标HIX随深度增加, 类蛋白组分荧光相对含量随深度降低, 并且同指示DOM分 子量的光谱斜率比值 $S_{\mathrm{R}}$ 分别呈显著的负相关和正相关关系。这说明从沉积物表层到深层，DOM由低分子量的类 蛋白组分向高分子量的类腐殖质组分过渡. 本研究结果对理解河口区沉积物中的孔隙水DOM分子量/活性模型 (pore water size/reactivity, PWSR) 以及DOM的生物有机地球化学过程提供了补充参考.

关键词珠江口, 沉积物, 溶解性有机质, 三维荧光光谱, 紫外可见吸收光谱

\section{1 引言}

溶解性有机质(dissolved organic matter, DOM) 是
指可以通过 $0.1 \sim 0.7 \mu \mathrm{m}$ 滤膜、组分结构复杂的有机混 合物，包括碳水化合物、蛋白质、木质素、有机酸和 腐殖质等(Burdige和Komada, 2015; Mopper等, 2007).

\footnotetext{
中文引用格式: 徐阳, 李朋辉, 张传伦, 王鹏. 2021. 珠江口沉积物溶解性有机质来源及光谱特征的空间变化. 中国科学: 地球科学, 51(1): 63-72, doi: 10.1360/ SSTe-2020-0054

英文引用格式: Xu Y, Li P, Zhang C, Wang P. 2021. Spectral characteristics of dissolved organic matter in sediment pore water from Pearl River Estuary. Science China Earth Sciences, 64(1): 52-61, https://doi.org/10.1007/s11430-020-9671-9
} 
DOM是海洋微型生物碳泵的主要研究对象, 在海洋碳 循环过程中起重要作用(Jiao等, 2010; 焦念志等, 2013; 张传伦, 2018; Zhang等, 2018; 张传伦等, 2019). 相对于 水体, 沉积物孔隙水DOM含量更高(Burdige和Zheng, 1998), 因此DOM在浓度差异下会以扩散的方式从沉 积物进入上层水体(Burdige等, 1999), 为水体微生物 所利用(Schiebel等, 2015; 周文楚, 2016). 研究发现海 洋沉积物每年向水体释放 $(177 \pm 56) \mathrm{Tg}$ C, 同河流向海 洋的碳输送量相当(Burdige和Homstead, 1994; Burdige 等, 1999), 可见沉积物是水体的重要碳源. 另外DOM 可与重金属形成有机络合物进而促进重金属的迁移吸 收, 在环境污染、生态治理领域的研究意义不可忽视 (Du Laing等, 2009; 何伟等, 2016).

以往的研究通常把海洋中的DOM来源分为内源 和外源两大类: 前者指水生生物的代谢产物和残体释 放; 后者指陆源高等植物的输入, 也包括人类活动排 放的污染物( Fu等, 2006; Chen等, 2013, 2016a, 2017a; $\mathrm{He}$ 等, 2014). 但相关培养实验结果显示, 一些典型的陆 源腐殖质荧光峰也可以通过微生物活动累积(Biers等, 2007; Hur等, 2009; 冯伟莹等, 2016). Burdige等(2004) 认为沉积物出现的陆源腐殖质可能来源于微生物作用 下海洋腐殖质的红移. 研究发现环境中的类蛋白荧光 组分同可水解氨基酸的浓度以及微生物代谢速率成正 相关, 因此把类蛋白组分归为藻类或者微生物来源的 新鲜有机质(Yamashita和Tanoue, 2003; Cammack等, 2004), 类酪氨酸和类色氨酸的比值可以指示蛋白组分 的降解程度(Mayer等, 1999).

Burdige和Komada(2015) 以分子量为标准, 构建沉 积物孔隙水DOM分子量/活性模型(pore water size/reactivity, PWSR). 在PWSR中, POM逐级降解, 首先形成 高分子量DOM(high-molecular-weight DOM, HMWDOM), 然后进一步降解成低分子量的DOM(low-molecular-weight DOM, LMW-DOM), 最终生成无机碳. 在 这一过程中也伴随产出惰性有机碳( recalcitrant dissolved organic carbon, RDOC). Komada等(2013)通过 对沉积物有机碳进行碳同位素模拟计算, 发现孔隙水 DOM由三部分构成: 活性、半活性和惰性DOM, 其中 惰性DOM可能来源于高成熟度的POM的降解. 沉积物 DOM的来源复杂, 不同来源的DOM在其循环过程中 的降解保存行为存在明显差异, 因此一直是沉积物 DOM研究的难点和重点.
河口作为陆地和海洋的过渡带, 环境因子、生物 反应过程以及有机质来源复杂, 是研究DOM的热点区 域(Maie等, 2007; Tremblay等, 2007; Wang等, 2013, 2014). 珠江口位于珠江三角洲地区下游, 具有淡水输 入源多, 咸淡水交换强烈的特点(郭威等, 2016), 对沉 积物溶解有机质的物质来源以及后期的循环过程产生 显著影响. 本研究的主要目的是通过利用紫外可见吸 收光谱和三维荧光光谱方法, 分析珠江口沉积物孔隙 水DOM的垂直和水平分布规律, 结合多个光谱指标探 究河口地区DOM的来源和后续降解保存过程.

\section{2 材料与方法}

\section{1 样品采集和处理}

沉积物样品采集于珠江口, 采样站位如图1所示. 本研究选取的三个站位分别代表了口内、河口混合 区、外海陆架三种不同的沉积环境. 于2016年8月, 利 用重力式柱状沉积物采样器(有机玻璃管内径 $5 \mathrm{~cm}$, 长 度 $50 \mathrm{~cm}$ ) 采集 $\mathrm{S} 1$ 和 $\mathrm{S} 2$ 站位沉积物(长度均为 $30 \sim 35 \mathrm{~cm}$ ); 2017年10月, 采集 $S 3$ 站位沉积柱 (长度为 $65 \sim 70 \mathrm{~cm}$ ). 沉 积柱以 $3 \mathrm{~cm}$ 为单位切割分样, 称取 $30 \mathrm{~g}$ 的沉积物, 以 $5000 \mathrm{r} \mathrm{min}{ }^{-1}$ 的速度离心 $20 \mathrm{~min}$, 将取得的上清液用 $0.22 \mu \mathrm{m}$ 的Millipore PES滤膜过滤, 用作后续光谱分析.

微生物的DNA抽提根据E.Z.N.A. ${ }^{\circledR}$ soil试剂盒 (Omega Bio-tek, Norcross, GA, U.S.) 说明书进行, DNA浓度和纯度利用NanoDrop2000进行检测, 利用 $1 \%$ 琼脂糖凝胶电泳检测DNA提取质量.

\section{2 光谱分析}

紫外可见吸收光谱采用UV-2600型分光光度计测 定, 用Milli-Q超纯水作空白, 扫描波长为200 800nm, 扫描间隔为 $1 \mathrm{~nm}$. 三维荧光光谱采用三维苂光分光光 度计(Horiba Aqualog)测定, 以Milli-Q超纯水做空白, 苂光光谱测定参数设置如下: 积分时间为 $1 \mathrm{~s}$, 扫描波 长范围为 $\lambda_{\mathrm{Ex}}: 240 \sim 450 \mathrm{~nm}, \lambda_{\mathrm{Em}}: 250 \sim 828 \mathrm{~nm}$; Ex步长为 $2 \mathrm{~nm}, \mathrm{Em}$ 步长为 $1.12 \mathrm{~nm}$. 所得三维荧光光谱扣除空白 样品(Milli-Q超纯水)的光谱信号后, 进行水拉曼归一 化处理(Murphy等, 2010), 然后利用DOMFluor工具包 在Matlab软件中进行PARAFAC分析(Stedmon和Bro, 2008). 文中用到的光谱参数腐质化指数(humification index, HIX)和光谱斜率比值 $\left(S_{\mathrm{R}}\right)$ 计算公式、指示意义 
以及相关引用文献见表 1.

\section{3 结果}

基于苂光光谱数据的PARAFAC模型共鉴定出 5 个 荧光组分(图2), 包含 2 个类蛋白组分 (C2 和 C5)和 3 个类 腐殖质组分 $(C 1 、 C 3$ 和C4)，同Coble(1996)、Coble等 (1998)的结果以及其他沉积物相关研究中的荧光组分 对照见表 2 . 类腐殖质组分 $\mathrm{C} 1$ 和 $\mathrm{C} 4$ 属于陆源腐殖质, 较 难被微生物降解, 类似于传统类腐殖质荧光团 $\mathrm{A}$, 在淡 水和海水环境中广泛存在. C3 的光谱特征与海洋来源 类腐殖质荧光团 $\mathrm{M}$ 相近，最近研究显示荧光团 $\mathrm{M}$ 也会 存在于非海洋环境中, 可能是微生物和光降解作用的
产物(Stedmon和Markager，2005; Helms等，2014). C2 与之前报道的类色氨酸荧光团 $\mathrm{T}$ 苂光特性相似，被认 为是降解程度较低的多肽类化合物; C5 同类酪氨酸荧 光团 $\mathrm{B}$ 苂光特性相似, 是降解程度较高的多肽类物质.

3 个站位 5 种荧光组分的荧光强度变化见图 3 , 其中 S1站位的苂光强度最高(图3a, 20.07 28.00R.U.), S2站 位次之(图3b，6.69 12.65R.U.), S3 站位最低(图3c, 1.80 7.72R.U.). S1站位类腐殖质组分 $\mathrm{C} 1 、 \mathrm{C} 3$ 和 $\mathrm{C} 4$ 的 荧光强度均随深度增加, 类蛋白组分 $\mathrm{C} 2$ 和 $\mathrm{C} 5$ 的荧光强 度随深度变化不明显. S2站位的 3 种类腐殖质组分荧光 强度都在1R.U.以下, 并且几乎不随深度发生变化, 2 种 类蛋白组分荧光强度在1.68 7.02R.U.范围内, 随深度 降低. S3站位的表层 $15 \mathrm{~cm}$ 以内, 5 种组分的荧光强度均

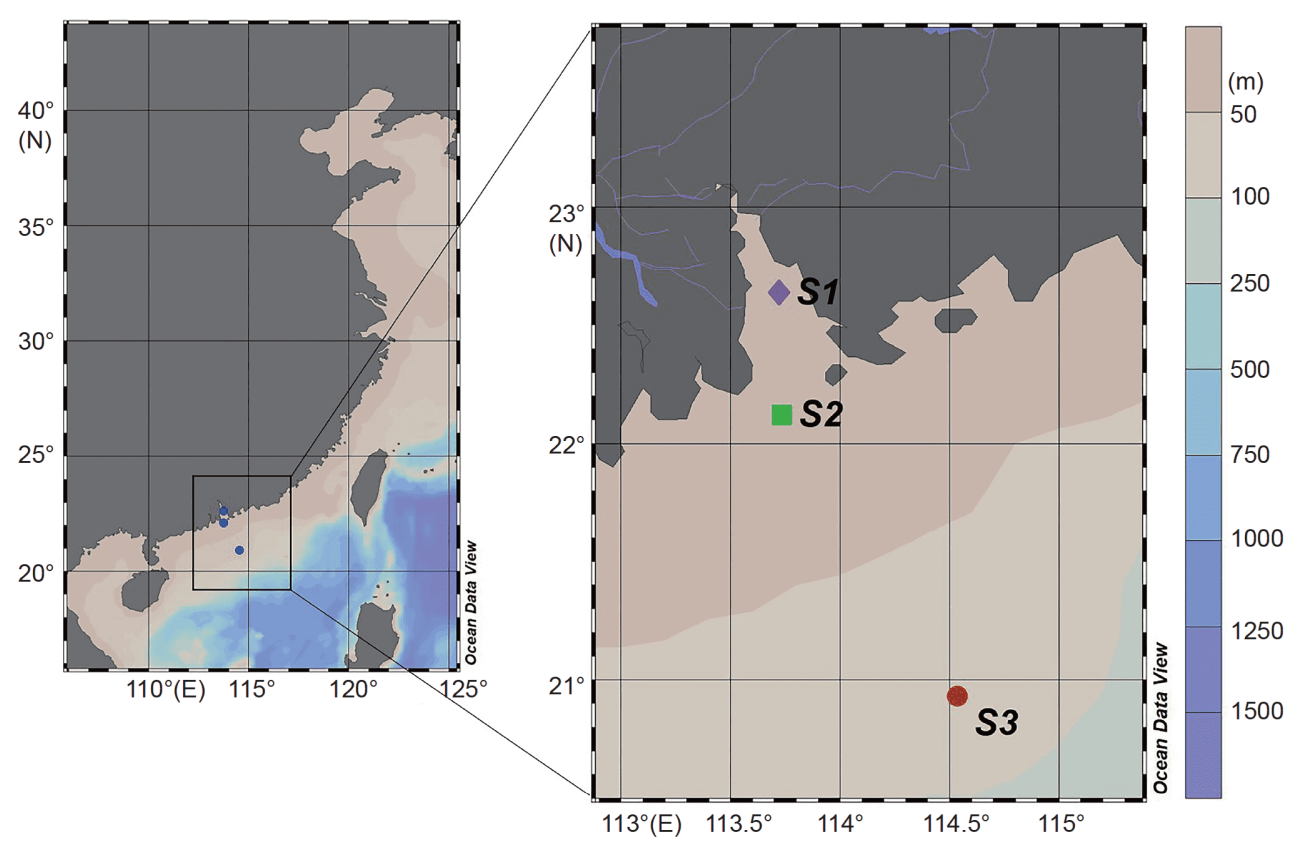

图 1 珠江口采样站位分布示意图

表 1 荧光光谱和吸收光谱参数计算及指示意义

\begin{tabular}{|c|c|c|}
\hline 指标 & 计算公式 & 指示意义 \\
\hline \multirow{4}{*}{ HIX } & \multirow{4}{*}{$\begin{array}{c}\lambda_{\mathrm{Ex}}=254 \mathrm{~nm} \\
\int_{435}^{480} I x / \int_{300}^{345} I x / \\
\text { (Zsolnay等, 1999) }\end{array}$} & $<4$, 生物来源溶解有机质 \\
\hline & & 4 6, 以微生物来源为主, 混有陆源腐殖质 \\
\hline & & $6 \sim 10$, 以陆源腐殖质为主, 混有微生物来源有机质 \\
\hline & & $\begin{array}{c}>16, \text { 以陆源腐殖质为主 } \\
\text { (Hur和Kim, 2009; Li等, 2014; Chen等, 2015, 2016b) }\end{array}$ \\
\hline$S_{\mathrm{R}}$ & $\begin{array}{l}S_{\mathrm{R}}=S_{275-295} / S_{350-400} \\
\text { (Helms等, 2008) }\end{array}$ & $\begin{array}{c}\text { 指示DOM分子量, 同分子量呈反相关 } \\
\text { (蔡明红等, 2012; Chen等, 2013, 2017b; 沈炼等, 2014; 王晓江等, 2018) }\end{array}$ \\
\hline
\end{tabular}



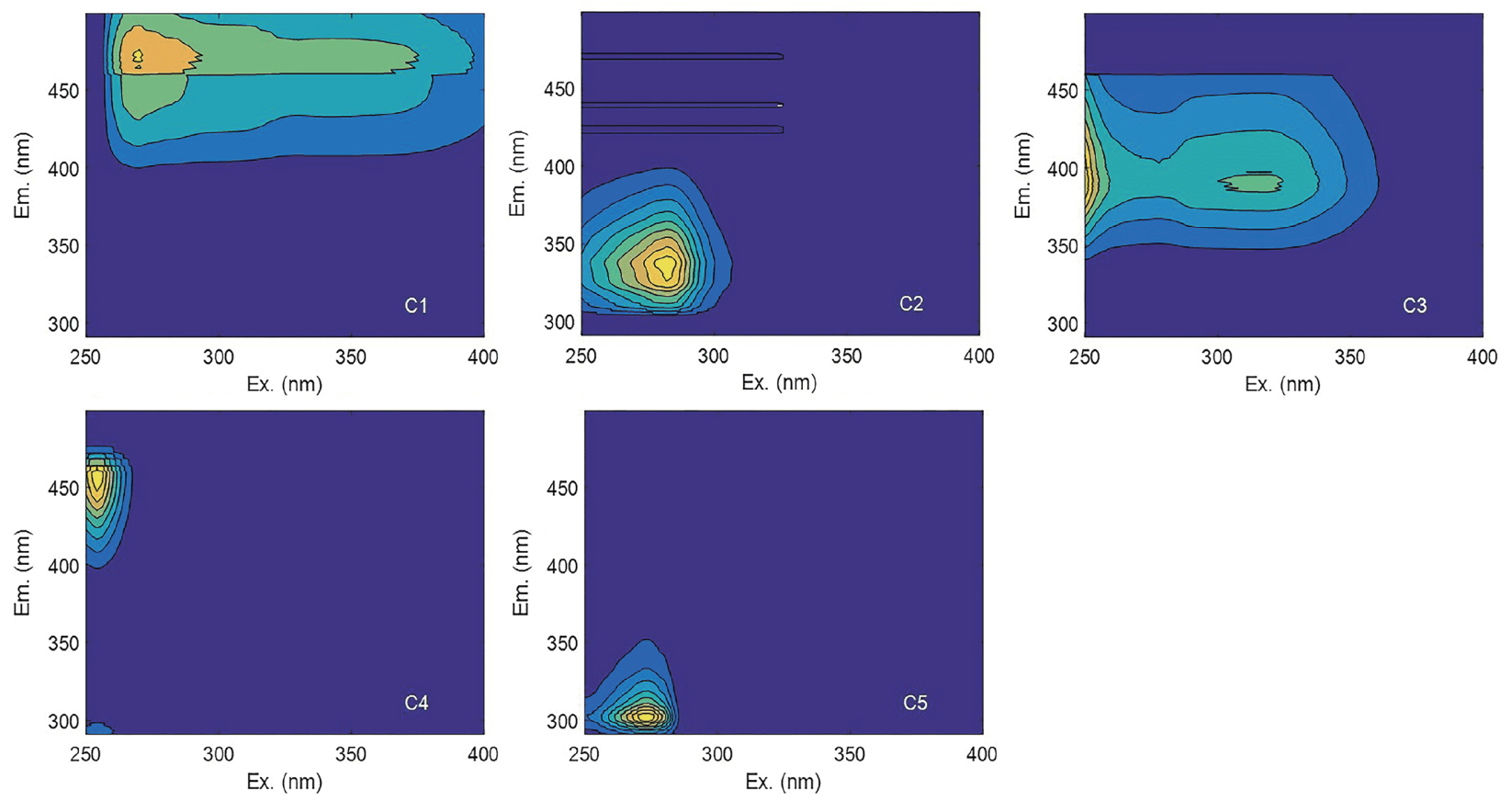

图 2 五种荧光组分的三维荧光光谱

$\mathrm{Ex}$ : 激发波长, Em: 发射波长

表 2 五种荧光组分特征描述和文献参考

\begin{tabular}{|c|c|c|c|c|}
\hline 组分 & $\mathrm{Ex} / \mathrm{Em}(\mathrm{nm})$ & Coble & 其他沉积物研究中的PARAFAC模型Ex/Em(nm) & 来源 \\
\hline $\mathrm{C} 1$ & $270 / 469$ & A & $\begin{array}{c}\text { C3, 260(355)/470(Ziegelgruber等, 2013) } \\
\text { C2, 265(365)/470(Wang等, 2013) }\end{array}$ & 陆源类腐殖质 \\
\hline $\mathrm{C} 2$ & $296 / 337$ & $\mathrm{~T}$ & $\begin{array}{c}\text { C8, 300/342(Chen等, 2013) } \\
\text { C2, 230(280)/344(Wang等, 2014) } \\
\text { C3, 225(275)/335(Wang等, 2013) }\end{array}$ & 类色氨酸 \\
\hline $\mathrm{C} 3$ & $250(318) / 391$ & M & $\begin{array}{c}\text { C2, 250(315)/<400(Hur等, 2014) } \\
\text { C1, 240(320)/410(Ziegelgruber等, 2013) } \\
\text { C4, <260(305)/376(Chen等, 2013) } \\
\text { C3, 320/388(Santín等, 2009) }\end{array}$ & 海源类腐殖质 \\
\hline $\mathrm{C} 4$ & $254 / 459$ & A & $\begin{array}{c}\mathrm{C} 1,<260(345) / 462 \text { (Chen等, 2013) } \\
\mathrm{C} 2,<260 / 454(\mathrm{Chen} \text { 等, 2013) } \\
\mathrm{C} 1,<250(335) / 450 \text { (Hur等, 2014) }\end{array}$ & 陆源类腐殖质 \\
\hline $\mathrm{C} 5$ & $274 / 303$ & $\mathrm{~B}$ & $\begin{array}{l}\text { C4, 275/304(Santín等, 2009) } \\
\text { C7, 275/326(Chen等, 2013) }\end{array}$ & 类酪氨酸 \\
\hline
\end{tabular}

随深度降低, C2 和 $\mathrm{C} 5$ 的下降趋势尤为明显, $15 \mathrm{~cm}$ 以下 各组分苂光强度基本保持稳定.

腐殖化指数(humification index, HIX)值越大, 代表 DOM的腐殖化程度越高, 稳定性越好, 在环境中的存 在时间越长. 本研究中 3 个站位沉积物DOM的HIX主 要在 $0.29 \sim 4.04$ 范围内 (图 $4 a$ ), 从大到小依次为
$\mathrm{S} 1>\mathrm{S} 3>\mathrm{S} 2$. 从垂直分布来看, $\mathrm{S} 1$ 和 $\mathrm{S} 3$ 站位的HIX值随 深度增加, 在S2站位, HIX随深度变化不明显. HIX是 腐殖质特征峰的积分面积同非腐殖质特征峰积分面积 的比值, 相当于类腐殖质和类蛋白的荧光强度的比值. 从图 $3 b$ 可以看出 $S 2$ 站位的类蛋白组分苂光强度远高 于类腐殖质组分, 即使在 $30 \mathrm{~cm}$ 的深度上类蛋白也高出 


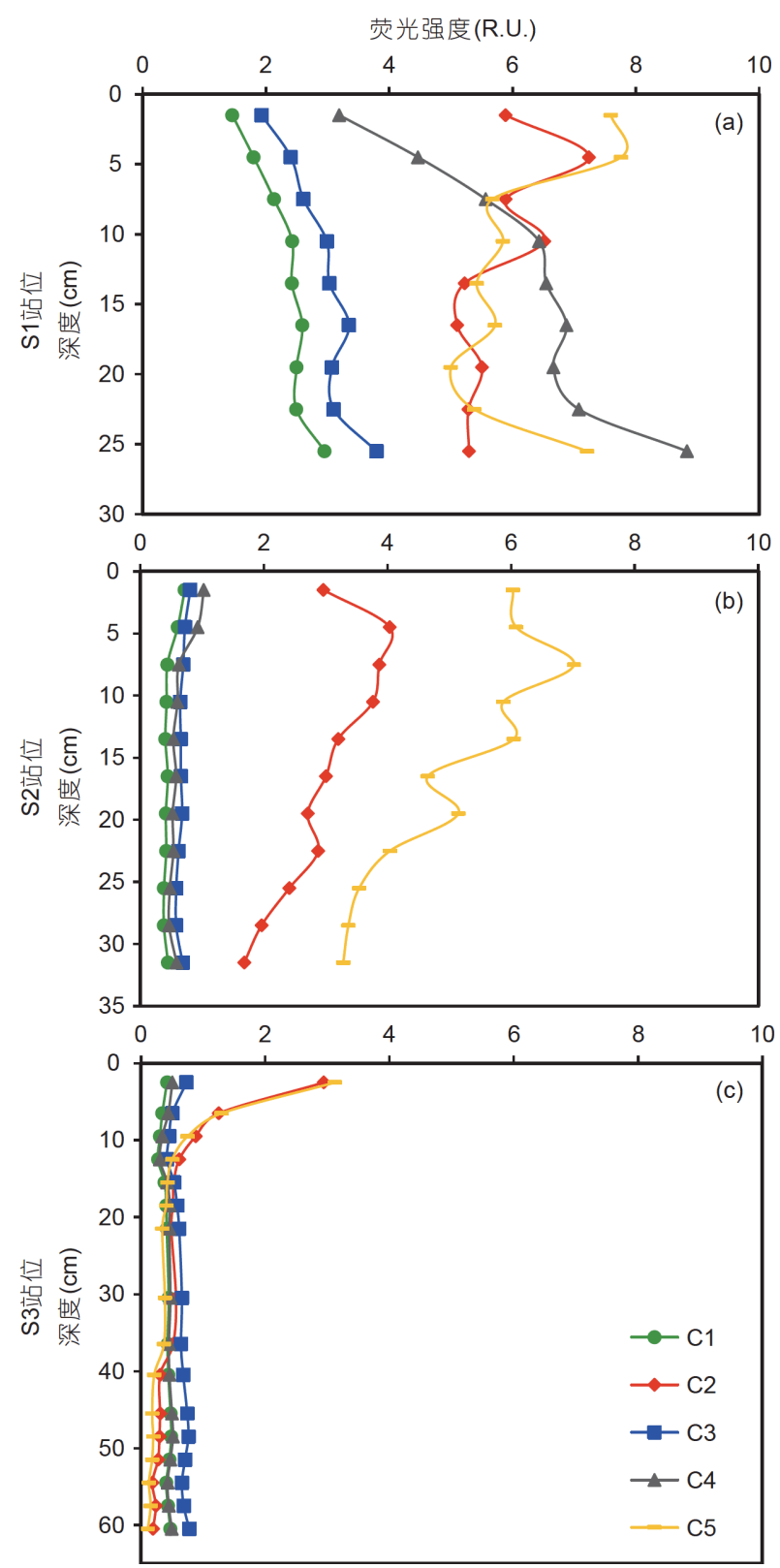

图 3 各组分荧光强度在不同站位的垂直分布特征 $\mathrm{C} 1 、 \mathrm{C} 4$, 陆源类腐殖质; $\mathrm{C} 3$, 海源类腐殖质; $\mathrm{C} 2$, 类色氨酸; $\mathrm{C}$, 类酪 氨酸

类腐殖质组分一个数量级, 因此虽然 $\mathrm{S} 2$ 站位的类蛋白 组分荧光强度随深度降低, 但HIX一直保持较低水平. 光谱斜率比值 $S_{\mathrm{R}}$ 在1 6范围内(图4b), 同Chen等(2016a) 关于西伯利亚海沉积物孔隙水 $\mathrm{DOM}$ 的数据相近. $S_{\mathrm{R}}$ 在 表层 $10 \mathrm{~cm}$ 以内从大到小依次为: $\mathrm{S} 3>\mathrm{S} 2>\mathrm{S} 1 ; 10 \mathrm{~cm}$ 以下, $\mathrm{S} 2$ 站位的 $S_{\mathrm{R}}$ 高于其他两个站位. 从垂直剖面看, 3 个站 位的 $S_{\mathrm{R}}$ 均随深度呈现出不同程度的降低趋势.

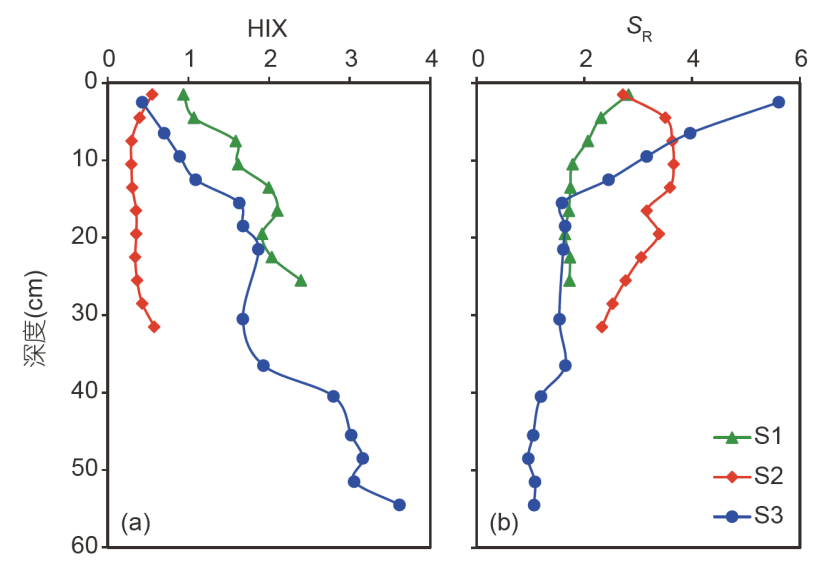

图 4 不同站位沉积柱DOM的腐质化指数HIX和光谱斜率 比值 $S_{\mathrm{R}}$ 的垂直分布特征

\section{4 讨论}

\section{1 沉积物孔隙水DOM的分布和来源}

类蛋白组分 $\mathrm{C} 2$ 和 $\mathrm{C} 5$ 菼光强度同沉积物的微生物 DNA浓度 $\left(\mu \mathrm{g} \mathrm{g}^{-1}\right.$, 以按照冻干前后的质量差转化成干 重沉积物)相关性分析见图5. 结果显示类色氨酸组分 $\mathrm{C} 2\left(R^{2}=0.69, P<0.01\right.$, 图5a) 同DNA的相关性比类酪氨 酸组分 $\mathrm{C} 5\left(R^{2}=0.40, P<0.05\right.$, 图5b)更加显著. Maie等 (2007)的研究显示来源于陆地植物的酚类化合物 (Ex/ $\mathrm{Em}$ : 五倍子酸: $<260 / 346 \mathrm{~nm}$; 丹宁酸: $275 / 313 \mathrm{~nm}$ )与类 蛋白组分的苂光峰重合, 水体DON浓度同类蛋白组分 有显著的相关性，但是同酚类化合物没有明显相关性. Burdige等(1999)认为沉积物中的类蛋白组分中既有新 鲜产出的活性DOM, 也包括降解程度很高的惰性 DOM. 本文中C 2 代表的类色氨酸组分同DNA浓度成 正相关, 很可能主要源于原位微生物的分解释放, 而 C5 代表的类酪氨酸组分可能部分属于酚类化合物, 因 此同原位微生物DNA浓度相关性较弱.

按照传统分类方法, 类腐殖质组分 $\mathrm{C} 1$ 和 $\mathrm{C} 4$ 属于陆 地来源, C3属于海洋来源(见表2). 但实验结果发现, 微 生物在培养过程中会产出惰性有机质, 典型的“陆源腐 殖质” A 峰和 C峰的荧光强度随时间累积 (Ogawa等, 2001; Stedmon和Markager, 2005; Gruber等, 2006; Hur 等, 2009; 冯伟莹等, 2016). Parlanti等(2000)发现藻类 在降解过程中会依次产出类蛋白、海源腐殖质和陆源 腐殖质苂光峰. 张凌等(2008)对珠江口沉积物有机质 的来源的研究结果显示, 细菌在沉积物有机质的碳循 环过程中扮演着重要角色. 但是在本研究中, 3 个站位 

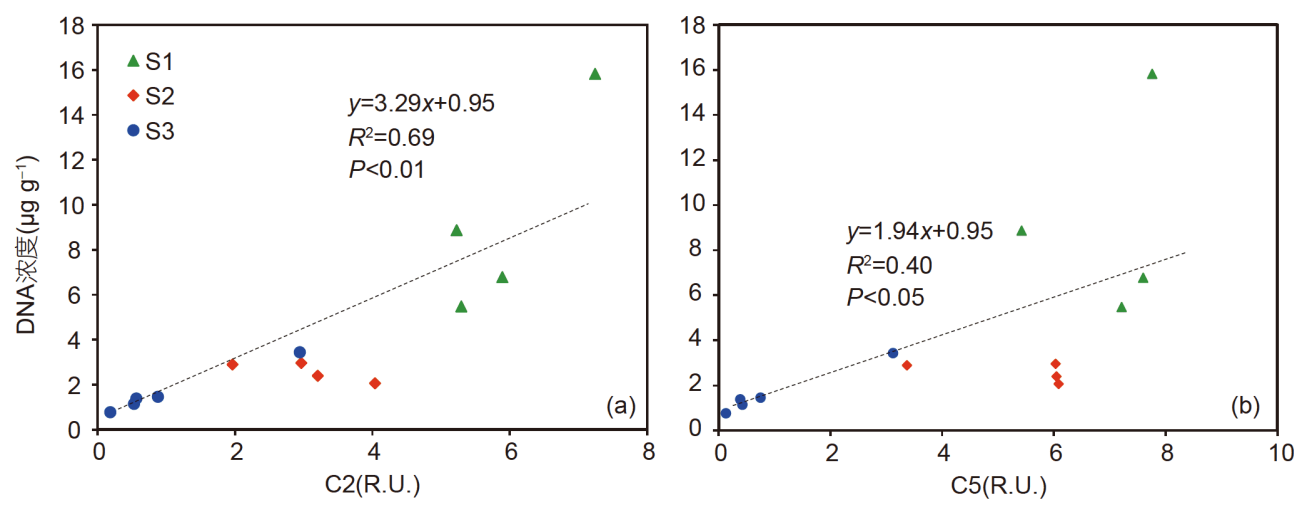

图 5 类蛋白组分荧光强度(C2、C5)同DNA浓度(干重沉积物)的相关性

沉积物的DNA浓度同陆源类腐殖质 $\mathrm{C} 1$ 和 $\mathrm{C} 4$ 的苂光强 度没有表现出显著的相关性 $\left(R^{2}\right.$ 分别为 0.39 和 0.34$)$, 说 明沉积物中微生物的分解释放不是类腐殖质的唯一来 源. 综上所述, 类腐殖质荧光组分的来源十分复杂, 陆 地输入、藻类降解和微生物代谢都能产出类似的苂光 峰, 因此仅仅根据荧光峰位置来确定其来源是不准 确的.

郭威(2016)和张凌等(2010)的研究结果显示珠江 口虎门区域附近(对应本文S1站位)有 $60 \%$ 左右的沉积 物有机质为陆地来源，近海区域(对应本文 $\mathrm{S} 3$ 站位)自 生来源有机质占 $80 \%$ 以上. 沿河口到近海，3个站位沉 积物有机质逐渐从陆源主导过度到海源主导. 对于 $\mathrm{S} 1$ 站位来说，虽然不能确定每一种类腐殖质荧光组分的 确切来源，但总体上陆源输入的贡献较大．关于河口 DOM的研究发现, 无论是水体还是沉积物, DOM的苂 光强度沿陆地-海洋逐渐降低, 进一步说明 $\mathrm{S} 1$ 站位整体 苂光强度较高主要是受到了陆源贡献的影响. 另外从 珠江口内到口外，随着水深的增加，沉积物粒径呈变 粗趋势, 砂质含量逐渐增加(郑建禄等, 1984; 时翠等, 2015; 赵利等, 2017), 沉积速率逐渐降低. 根据文献数 据，S1、S2 和S3站位附近区域沉积速率分别为5.36、 1.58 和 $0.27 \mathrm{~cm} \mathrm{a}^{-1}$ (吴良基和范时清，1987; 刘志勇等, 2010). 较高的沉积速率和细粒径的沉积颗粒利于有机 质的保存, 这也可以解释S1站位沉积物孔隙水DOM含 量较高. S2 和S3站位的的类腐殖质荧光组分分布十分 相似，代表陆源腐殖质的 $\mathrm{C} 1$ 和 $\mathrm{C} 4$ 以及代表海源类腐殖 质的 $\mathrm{C} 3$ 的质荧光强度十分接近 $(<1$ R.U. $)$, 并且随深度 变化趋势不明显，因此三种类腐殖质荧光组分可能有 相同的来源. 根据文献数据可知 $\mathrm{S} 2$ 和 $\mathrm{S} 3$ 两个站位的沉
积物有机质以海洋来源为主(郭威，2016; 张凌等, 2010)，但3种类腐殖质同原位微生物DNA浓度的相关 性低于类蛋白组分 $\mathrm{C} 2$, 因此类腐殖质的来源应该既有 沉积物原位微生物的贡献，也包括水生生物的分解释 放. 今后可以借助碳同位素方法来验证这一推测是否 合理. 由于沉积物DOM来源的复杂性, 有研究曾用降 解程度来表征各种荧光组分，类蛋白、海源和陆源类 腐殖质荧光组分所代表的有机质的微生物可利用性逐 渐降低，降解程度依次升高(Burdige等，2004; Komada 等, 2004). 按照这一划分方法, S1站位类腐殖质苂光强 度和HIX值明显高于其他两个站位，说明该站位沉积 物DOM含有大量高成熟的腐殖质类化合物, $\mathrm{S} 2$ 和 $\mathrm{S} 3$ 站 位主要由新鲜的DOM构成.

\subsection{DOM的PWSR模型在珠江口沉积物中的应用}

在PWSR模型中，HMW-DOM主要指容易被分解 的大分子蛋白和多糖类有机质，而LMW-DOM属于降 解程度较高的惰性有机碳(Burdige和Komada，2015). 在正常沉积条件下，沉积物中的活性有机碳含量和微 生物丰度随深度逐渐降低(Fischer等, 2002), 本文中的 细菌DNA浓度也符合这一分布规律。按照PWSR模型 的解释, HMW-DOM应该主要赋存在表层沉积物中, 而深层沉积物以成熟度更高的LMW-DOM为主，因此 DOM的分子量应沿深度逐渐降低. 但是在本研究中 3 个站位的 $S_{\mathrm{R}}$ 值均随深度降低, 说明DOM的分子量逐渐 增加，一些沉积物孔隙水的研究结果也呈现出相同的 变化规律(Orem和Gaudette，1984; Chin和Gschwend, 1991; Chin等, 1994). 同时, 类蛋白荧光组分的相对含 量随深度降低(S1：67 43\%; S2: 86 74\%; S3:79 15\%), 
HIX值随深度增加(图4a), 说明孔隙水中腐殖质组分逐 渐增多，整体DOM分子量逐渐增加. 这几种指标的分 布规律同PWSR模型不吻合，这是因为在Burdige的模 型中HMW-DOM主要指易降解的大分子蛋白和多糖, 腐殖酸类化合物则归为LMW-DOM. 而本文中 $S_{\mathrm{R}}$ 值同 类蛋白组分的相对含量呈现出显著的正相关(图6a), 同HIX成显著负相关(图6b), 说明类蛋白组分随深度减 少使整体DOM的分子量变大，腐质化程度增加. 结果 表明本文中的类蛋白组分比类腐殖质组分的分子量更 低. 一些培养实验结果也出现了类似的规律, 随着培养 时间增加, 类蛋白组分减少, 类腐殖质组分累积, 并且 整体DOM的分子量逐渐增加(Rosenstock等，2005; Biers等, 2007; Hur等, 2009). 但并非在所有研究中类
蛋白组分都属于LMW-DOM， $S_{\mathrm{R}}$ 或 $S_{275-295}$ 同类蛋白组 分相对含量的相关性并不稳定(图7b和7a), 甚至存在 负相关的情况(蔡明红等, 2012). 这些证据表明沉积物 中活性DOM既包括高分子量的蛋白，也包括小分子量 的糖类和氨基酸等(Homann和Grigal, 1992; 王静等, 2008，2015). 惰性DOM既包括小分子RDOC，也包括 聚合态的腐殖质，因此不能仅仅用分子量来衡量DOM 的降解程度.

影响DOM组分构成的因素有很多，例如沉积速 率、沉积物粒度、沉积物的氧化还原条件(Komada等, 2004；Burdige，2007)、铁锰离子浓度(Deflandre等, 2002; O'loughlin和Chin, 2004)以及微生物丰度和多样 性(Hur等，2009; Oni等，2015)等. 在不同的条件下，

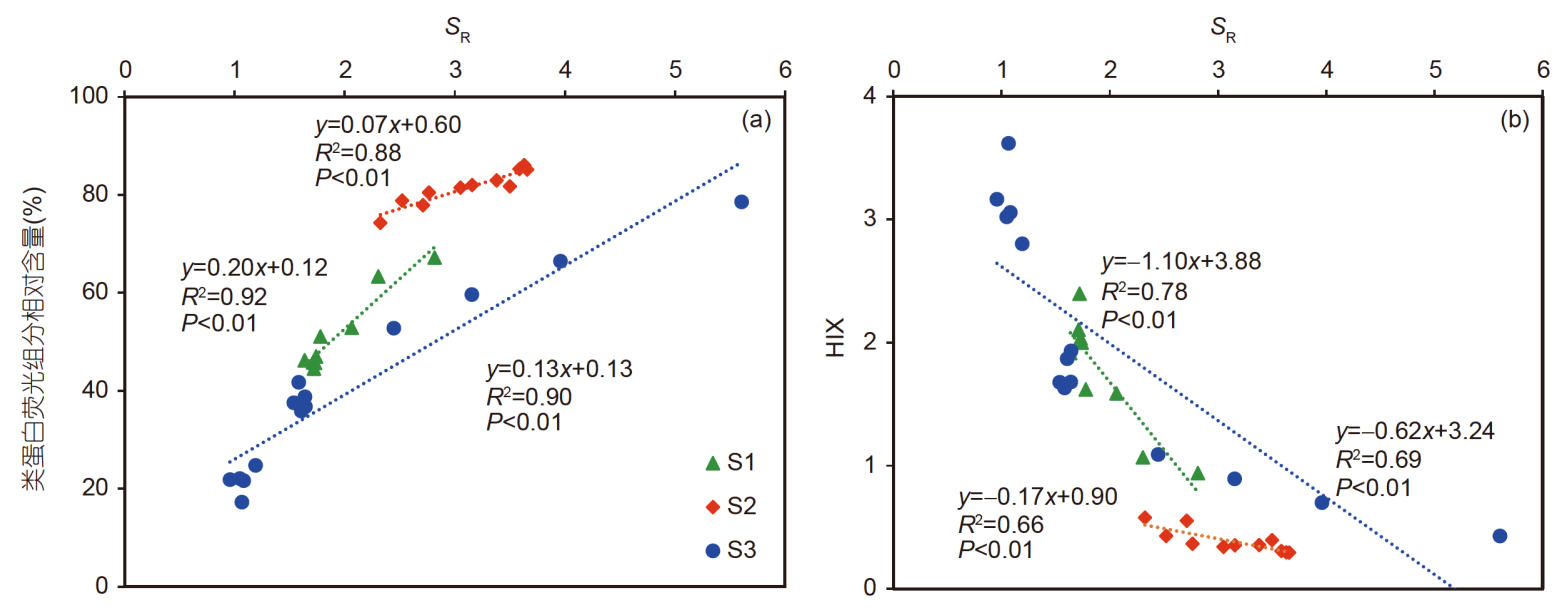

图 6 类蛋白组分相对含量 $(\mathrm{C} 2 \%+\mathrm{C} 5 \%)$ 和HIX同 $S_{\mathrm{R}}$ 的相关性

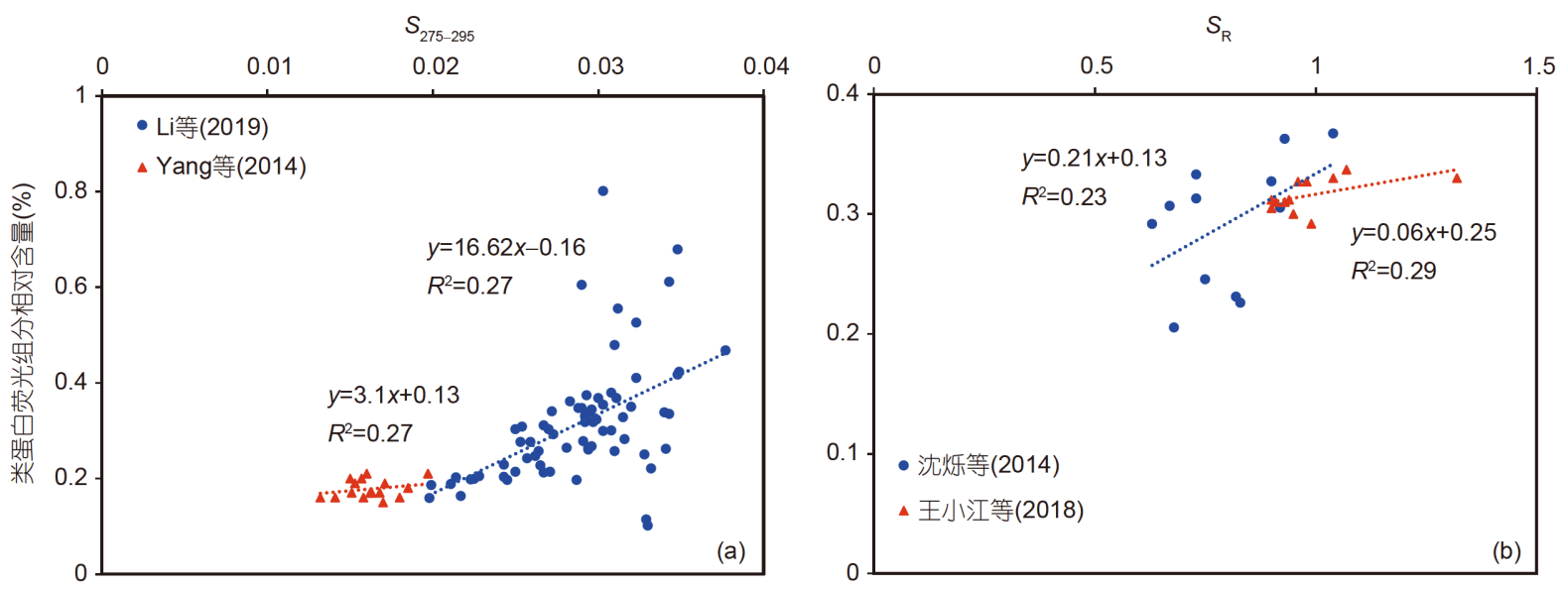

图 7 文献中 $\mathbf{S 2 7 5 - 2 9 5}$ 和 $S_{\mathrm{R}}$ 同类蛋白荧光组分相对含量的相关性

Yang等(2014)、沈伢等(2014)、王晓江等(2018)和Li等(2019) 
DOM的组分和分子量分布有很大差异. PWSR模型只 是从分子量角度阐述POM在沉积物中逐级演变为DIC 的过程，而自然环境条件复杂，DOM的分子量和降解 程度和之间的对应关系没有唯一确定的标准.

\section{5 结论}

珠江口沉积物DOM由 5 种苂光组分构成：类腐殖 质荧光组分 $\mathrm{C} 1 、 \mathrm{C} 3$ 和 $\mathrm{C} 4$, 类蛋白荧光组分 $\mathrm{C} 2$ 和 $\mathrm{C} 5 . \mathrm{C} 2$ 的荧光强度同沉积物微生物DNA浓度表现出显著的相 关性，说明类蛋白苂光组分主要来源于原位微生物的 分解释放, C5 同DNA浓度的相关性较弱，可能是混入 了苂光峰位置相近的酚类化合物. 类腐殖质荧光组分 的来源比较复杂，本文没有用传统的荧光峰位置法对 类腐殖质组分的来源进行划分，而是结合有机质来源 的贡献和荧光组分的分布特征来探讨 3 各站位类腐殖 质组分的来源. S1站位类腐殖质组分荧光强度高, 受陆 源输入的影响较大. $\mathrm{S} 2$ 和 $\mathrm{S} 3$ 站位的 3 种类腐殖质的苂光 强度都很低, 并且随深度变化趋势不明显, 同原位微生 物DNA浓度的相关性低于类蛋白组分 $\mathrm{C} 2$, 推测是水体 和沉积物中藻类微生物的混合来源. 从沉积物表层到 深层，DOM由低分子量的类蛋白逐渐向高分子量的类 腐殖质苂光组分过渡，说明分子量和DOM的活性之间 的对应关系在复杂的自然环境中不一定成立.

致谢 本研究所使用的沉积柱样品由陈松泽、谢伟、陶 建昌采集提供, 在此表示感谢.

\section{参考文献}

蔡明红, 肖宜华, 王峰, 陆志波, 黄清辉. 2012. 北极孔斯峡湾表层沉 积物中溶解有机质的来源与转化历史. 海洋学报, 34: 102-113

冯伟荣, 朱元荣, 吴丰昌, 张旭, 张琛. 2016. 太湖水体溶解性有机质 荧光特征及其来源解析. 环境科学学报, 36: 475-482

郭威, 叶丰, 连忠廉, 贾国东. 2016. 珠江口水体有机碳的季节性变化 热带海洋学报, 35: 40-50

郭威. 2016. 珠江口水体和沉积物有机碳的来源及其生物地球化学 特征. 博士学位论文. 广州: 中国科学院广州地球化学研究所. 1159

何伟, 白泽林, 李一龙, 孔祥臻, 刘文秀, 杨晨, 杨斌, 徐福留. 2016. 水 生生态系统中溶解性有机质表生行为与环境效应研究. 中国科 学: 地球科学, 46: 341-355

焦念志, 张传伦, 李超, 王晓雪, 党宏月, 曾庆璐, 张锐, 张瑶, 汤凯, 张
子莲, 徐大鹏. 2013. 海洋微型生物碳洜储碳机制及气候效应. 中 国科学: 地球科学, 43: 1-18

刘志勇, 潘少明, 程功饴, 李向东. 2010. 珠江口沉积物 ${ }^{210} \mathrm{~Pb}$ 分布特征 及环境意义. 沉积学报, 28: 166-175

沈炼, 王育来, 杨长明, 杨殿海. 2014. 南泪河不同排口表层沉积物 DOM光谱特征. 中国环境科学, 34: 2351-2361

时翠, 甘华阳, 夏真, 林进清. 2015. 珠江口内伶仃洋表层沉积物粒度 特征及其运移趋势. 海洋地质与第四纪地质, 35: 13-20

王静, 郭建阳, 秦海波, 徐文坡, 㚞宇红. 2015. 乌江水库水体中有机 胶粒的三维苂光特征研究. 地球与环境, 43: 104-110

王静, 吴丰昌, 王立英, 廖海清, 黎文. 2008. 超滤、三维苂光光谱与 高效体积排阻色谱联合表征地表水环境中溶解有机质的性质. 环境科学, 29: 3027-3034

王晓江, 黄廷林, 李楠, 周石否, 李扬, 张海涵, 任梦甜. 2018. 峡谷分 层型水源水库表层沉积物溶解性有机物光谱特征. 湖泊科学, 30 : $1625-1635$

吴良基, 范时清. 1987. 珠江口外海区沉积物 ${ }^{210} \mathrm{~Pb}$ 波动与沉积环境因 子关系研究. 热带海洋, 6: 1-9

张传伦. 2018. 微型生物碳百—海洋生物地球化学研究的新模式. 中国科学: 地球科学, 48: 805-808

张传伦, 孙军, 刘纪化, 蔡阮鸿. 2019. 海洋微型生物碳葲理论的发展 与展望. 中国科学: 地球科学, 49: 1933-1944

张凌, 陈繁荣, 杨永强, 张德荣. 2008. 珠江口外近海沉积有机质化学 及稳定同位素组成的早期成岩改变. 海洋学报, 30: 43-51

张凌, 陈繁荣, 殷克东, 吕荣, 杨永强, 张德荣. 2010. 珠江口及近海表 层沉积有机质的特征和来源. 热带海洋学报, 29: 98-103

赵利, 蔡观强, 钟和贤, 徐子英, 李波, 李顺, 田成静. 2017. 南海北部 陆架海域表层沉积物地球化学特征及地质意义. 地质学刊, 41 : 103-111

郑建禄, 何锦文, 朱克勤. 1984. 珠江口海域重金属的河口化学研究 $-\mathrm{V}$.表层沉积物中黏土矿物的分布. 海洋学报, 6: 197-205

周文楚. 2016. 厦门近岸表层水体微型生物对沉积物溶解有机质添 加的响应及转化研究. 硕士学位论文. 厦门: 厦门大学. 1-89

Biers E J, Zepp R G, Moran M A. 2007. The role of nitrogen in chromophoric and fluorescent dissolved organic matter formation. Mar Chem, 103: 46-60

Burdige D J. 2007. Preservation of organic matter in marine sediments: Controls, mechanisms, and an imbalance in sediment organic carbon budgets? Chem Rev, 107: 467-485

Burdige D J, Homstead J. 1994. Fluxes of dissolved organic carbon from Chesapeake Bay sediments. Geochim Cosmochim Acta, 58: $3407-3424$

Burdige D J, Zheng S. 1998. The biogeochemical cycling of dissolved organic nitrogen in estuarine sediments. Limnol Oceanogr, 43: $1796-1813$

Burdige D J, Berelson W M, Coale K H, McManus J, Johnson K S. 1999. Fluxes of dissolved organic carbon from California 
continental margin sediments. Geochim Cosmochim Acta, 63: $1507-1515$

Burdige D J, Kline S W, Chen W. 2004. Fluorescent dissolved organic matter in marine sediment pore waters. Mar Chem, 89: 289-311

Burdige D J, Komada T. 2015. Sediment pore waters. In: Hansell D A, Carlson C A, eds. Biogeochemistry of Marine Dissolved Organic Matter. London: Academic Press. 535-577

Cammack W K L, Kalff J, Prairie Y T, Smith E M. 2004. Fluorescent dissolved organic matter in lakes: Relationships with heterotrophic metabolism. Limnol Oceanogr, 49: 2034-2045

Chen M, Maie N, Parish K, Jaffé R. 2013. Spatial and temporal variability of dissolved organic matter quantity and composition in an oligotrophic subtropical coastal wetland. Biogeochemistry, 115: 167-183

Chen M, Lee J H, Hur J. 2015. Effects of sampling methods on the quantity and quality of dissolved organic matter in sediment pore waters as revealed by absorption and fluorescence spectroscopy. Environ Sci Pollut Res, 22: 14841-14851

Chen M, Kim J H, Nam S I, Niessen F, Hong W L, Kang M H, Hur J. 2016a. Production of fluorescent dissolved organic matter in Arctic Ocean sediments. Sci Rep, 6: 39213

Chen M, Kim S, Park J E, Kim H S, Hur J. 2016b. Effects of dissolved organic matter (DOM) sources and nature of solid extraction sorbent on recoverable DOM composition: Implication into potential lability of different compound groups. Anal Bioanal Chem, 408: 4809-4819

Chen M, Kim J H, Choi J, Lee Y K, Hur J. 2017a. Biological early diagenesis and insolation-paced paleoproductivity signified in deep core sediment organic matter. Sci Rep, 7: 1581

Chen M, Kim S H, Jung H J, Hyun J H, Choi J H, Lee H J, Huh I A, Hur J. 2017b. Dynamics of dissolved organic matter in riverine sediments affected by weir impoundments: Production, benthic flux, and environmental implications. Water Res, 121: 150-161

Chin Y, Gschwend P M. 1991. The abundance, distribution, and configuration of porewater organic colloids in recent sediments. Geochim Cosmochim Acta, 55: 1309-1317

Chin Y P, Aiken G, O’Loughlin E. 1994. Molecular weight, polydispersity, and spectroscopic properties of aquatic humic substances. Environ Sci Technol, 28: 1853-1858

Coble P G. 1996. Characterization of marine and terrestrial DOM in seawater using excitation-emission matrix spectroscopy. Mar Chem, 51: $325-346$

Coble P G, Del Castillo C E, Avril B. 1998. Distribution and optical properties of CDOM in the Arabian Sea during the 1995 Southwest Monsoon. Deep-Sea Res Part II-Top Stud Oceanogr, 45: 2195-2223

Deflandre B, Mucci A, Gagné J P, Guignard C, Sundby B. 2002. Early diagenetic processes in coastal marine sediments disturbed by a catastrophic sedimentation event. Geochim Cosmochim Acta, 66:
$2547-2558$

Fischer H, Wanner S C, Pusch M. 2002. Bacterial abundance and production in river sediments as related to the biochemical composition of particulate organic matter (POM). Biogeochemistry, 61: $37-55$

Fu P, Wu F, Liu C Q, Wei Z, Bai Y, Liao H. 2006. Spectroscopic characterization and molecular weight distribution of dissolved organic matter in sediment porewaters from Lake Erhai, Southwest China. Biogeochemistry, 81: 179-189

Gruber D F, Simjouw J P, Seitzinger S P, Taghon G L. 2006. Dynamics and characterization of refractory dissolved organic matter produced by a pure bacterial culture in an experimental predator-prey system. Appl Environ Microbiol, 72: 4184-4191

He L, Yuan D, Zhu N, Guo X, Guo N, Chen L. 2014. The spectral characteristics of dissolved organic matter from sediments in Lake Baiyangdian, North China. J Great Lakes Res, 40: 684-691

Helms J R, Stubbins A, Ritchie J D, Minor E C, Kieber D J, Mopper K. 2008. Absorption spectral slopes and slope ratios as indicators of molecular weight, source, and photobleaching of chromophoric dissolved organic matter. Limnol Oceanogr, 53: 955-969

Helms J R, Mao J, Stubbins A, Schmidt-Rohr K, Spencer R G M, Hernes P J, Mopper K. 2014. Loss of optical and molecular indicators of terrigenous dissolved organic matter during long-term photobleaching. Aquat Sci, 76: 353-373

Homann P S, Grigal D F. 1992. Molecular weight distribution of soluble organics from laboratory-manipulated surface soils. Soil Sci Soc Am J, 56: 1305-1310

Hur J, Park M H, Schlautman M A. 2009. Microbial transformation of dissolved leaf litter organic matter and its effects on selected organic matter operational descriptors. Environ Sci Technol, 43: 2315-2321

Hur J, Kim G. 2009. Comparison of the heterogeneity within bulk sediment humic substances from a stream and reservoir via selected operational descriptors. Chemosphere, 75: 483-490

Hur J, Lee B M, Shin K H. 2014. Spectroscopic characterization of dissolved organic matter isolates from sediments and the association with phenanthrene binding affinity. Chemosphere, 111: 450-457

Jiao N, Herndl G J, Hansell D A, Benner R, Kattner G, Wilhelm S W, Kirchman D L, Weinbauer M G, Luo T, Chen F, Azam F. 2010. Microbial production of recalcitrant dissolved organic matter: Longterm carbon storage in the global ocean. Nat Rev Microbiol, 8: 593599

Komada T, Reimers C E, Luther Iii G W, Burdige D J. 2004. Factors affecting dissolved organic matter dynamics in mixed-redox to anoxic coastal sediments. Geochim Cosmochim Acta, 68: 40994111

Komada T, Burdige D J, Crispo S M, Druffel E R M, Griffin S, Johnson L, Le D. 2013. Dissolved organic carbon dynamics in anaerobic 
sediments of the Santa Monica Basin. Geochim Cosmochim Acta, 110: $253-273$

Du Laing G, Rinklebe J, Vandecasteele B, Meers E, Tack F M G. 2009. Trace metal behaviour in estuarine and riverine floodplain soils and sediments: A review. Sci Total Environ, 407: 3972-3985

Li X, Guo H, Zheng H, Xiu W, He W, Ding Q. 2019. Roles of different molecular weights of dissolved organic matter in arsenic enrichment in groundwater: Evidences from ultrafiltration and EEM-PARAFAC. Appl Geochem, 104: 124-134

Li Y, Wang S, Zhang L, Zhao H, Jiao L, Zhao Y, He X. 2014. Composition and spectroscopic characteristics of dissolved organic matter extracted from the sediment of Erhai Lake in China. J Soils Sediments, 14: 1599-1611

Maie N, Scully N M, Pisani O, Jaffé R. 2007. Composition of a proteinlike fluorophore of dissolved organic matter in coastal wetland and estuarine ecosystems. Water Res, 41: 563-570

Mayer L M, Schick L L, Loder Iii T C. 1999. Dissolved protein fluorescence in two maine estuaries. Mar Chem, 64: 171-179

Mopper K, Stubbins A, Ritchie J D, Bialk H M, Hatcher P G. 2007. Advanced instrumental approaches for characterization of marine dissolved organic matter: Extraction techniques, mass spectrometry, and nuclear magnetic resonance spectroscopy. Chem Rev, 107: 419442

Murphy K R, Butler K D, Spencer R G M, Stedmon C A, Boehme J R, Aiken G R. 2010. Measurement of dissolved organic matter fluorescence in aquatic environments: An interlaboratory comparison. Environ Sci Technol, 44: 9405-9412

O’Loughlin E J, Chin Y P. 2004. Quantification and characterization of dissolved organic carbon and iron in sedimentary porewater from Green Bay, WI, USA. Biogeochemistry, 71: 371-386

Ogawa H, Amagai Y, Koike I, Kaiser K, Benner R. 2001. Production of refractory dissolved organic matter by bacteria. Science, 292: $917-$ 920

Oni O E, Schmidt F, Miyatake T, Kasten S, Witt M, Hinrichs K U, Friedrich M W. 2015. Microbial communities and organic matter composition in surface and subsurface sediments of the Helgoland mud area, North Sea. Front Microbiol, 6: doi: 10.3389/ fmicb.2015.01290

Orem W H, Gaudette H E. 1984. Organic matter in anoxic marine pore water: Oxidation effects. Org Geochem, 5: 175-181

Parlanti E, Wörz K, Geoffroy L, Lamotte M. 2000. Dissolved organic matter fluorescence spectroscopy as a tool to estimate biological activity in a coastal zone submitted to anthropogenic inputs. Org Geochem, 31: 1765-1781

Rosenstock B, Zwisler W, Simon M. 2005. Bacterial consumption of humic and non-humic low and high molecular weight DOM and the effect of solar irradiation on the turnover of labile DOM in the Southern Ocean. Microbial Ecol, 50: 90-101

Santín C, Yamashita Y, Otero X L, Álvarez M Á, Jaffé R. 2009. Characterizing humic substances from estuarine soils and sediments by excitation-emission matrix spectroscopy and parallel factor analysis. Biogeochemistry, 96: 131-147

Schiebel H N, Wang X, Chen R F, Peri F. 2015. Photochemical release of dissolved organic matter from resuspended salt marsh sediments. Estuaries Coasts, 38: 1692-1705

Stedmon C A, Bro R. 2008. Characterizing dissolved organic matter fluorescence with parallel factor analysis: A tutorial. Limnol Oceanogr Methods, 6: 572-579

Stedmon C A, Markager S. 2005. Tracing the production and degradation of autochthonous fractions of dissolved organic matter by fluorescence analysis. Limnol Oceanogr, 50: 1415-1426

Tremblay L B, Dittmar T, Marshall A G, Cooper W J, Cooper W T. 2007. Molecular characterization of dissolved organic matter in a North Brazilian mangrove porewater and mangrove-fringed estuaries by ultrahigh resolution Fourier Transform-Ion Cyclotron Resonance mass spectrometry and excitation/emission spectroscopy. Mar Chem, 105: 15-29

Wang Y, Zhang D, Shen Z, Chen J, Feng C. 2014. Characterization and spacial distribution variability of chromophoric dissolved organic matter (CDOM) in the Yangtze Estuary. Chemosphere, 95: 353362

Wang Y, Zhang D, Shen Z, Feng C, Chen J. 2013. Revealing sources and distribution changes of dissolved organic matter (DOM) in pore water of sediment from the Yangtze Estuary. PLoS ONE, 8: e76633

Yamashita Y, Tanoue E. 2003. Chemical characterization of protein-like fluorophores in DOM in relation to aromatic amino acids. Mar Chem, 82: 255-271

Yang L, Choi J H, Hur J. 2014. Benthic flux of dissolved organic matter from lake sediment at different redox conditions and the possible effects of biogeochemical processes. Water Res, 61: 97-107

Zhang C, Dang H, Azam F, Benner R, Legendre L, Passow U, Polimene L, Robinson C, Suttle C A, Jiao N. 2018. Evolving paradigms in biological carbon cycling in the ocean. Natl Sci Rev, 5: 481-499

Ziegelgruber K L, Zeng T, Arnold W A, Chin Y P. 2013. Sources and composition of sediment pore-water dissolved organic matter in prairie pothole lakes. Limnol Oceanogr, 58: 1136-1146

Zsolnay A, Baigar E, Jimenez M, Steinweg B, Saccomandi F. 1999. Differentiating with fluorescence spectroscopy the sources of dissolved organic matter in soils subjected to drying. Chemosphere, 38: $45-50$

(责任编委: 李超) 